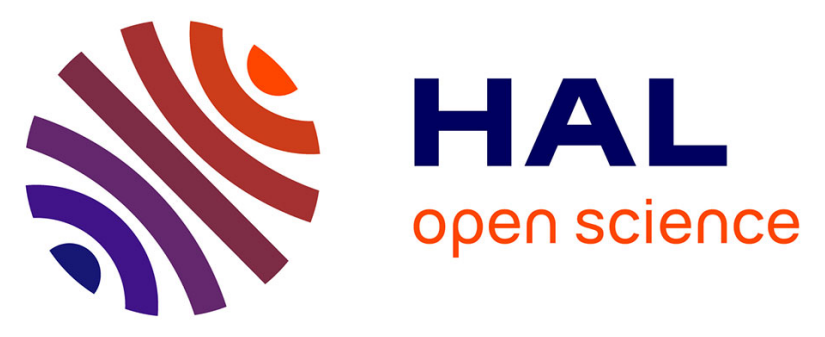

\title{
Preparation of nano cationic liposome as carrier membrane for polyhexamethylene biguanide chloride through various methods utilizing higher antibacterial activities with low cell toxicity
}

Elnaz Ahani, Majid Montazer, Tayebeh Toliyat, Mahnaz Mahmoudi Rad, Tina Harifi

\section{To cite this version:}

Elnaz Ahani, Majid Montazer, Tayebeh Toliyat, Mahnaz Mahmoudi Rad, Tina Harifi. Preparation of nano cationic liposome as carrier membrane for polyhexamethylene biguanide chloride through various methods utilizing higher antibacterial activities with low cell toxicity. Journal of Microencapsulation, 2017, 34 (2), pp.121-131. 10.1080/02652048.2017.1296500 . hal-02006776

\author{
HAL Id: hal-02006776 \\ https://hal.science/hal-02006776
}

Submitted on 4 Feb 2019

HAL is a multi-disciplinary open access archive for the deposit and dissemination of scientific research documents, whether they are published or not. The documents may come from teaching and research institutions in France or abroad, or from public or private research centers.
L'archive ouverte pluridisciplinaire HAL, est destinée au dépôt et à la diffusion de documents scientifiques de niveau recherche, publiés ou non, émanant des établissements d'enseignement et de recherche français ou étrangers, des laboratoires publics ou privés. 


\title{
Preparation of Nano Cationic Liposome as Carrier Membrane for Polyhexamethylene Biguanide Chloride through Various Methods Utilizing Higher Antibacterial Activities with Low Cell Toxicity
}

\author{
Elnaz Ahani, Majid Montazer, Taiebeh Toliat, Mahnaz Mahmoudi Rad \& Tina \\ Harifi
}

To cite this article: Elnaz Ahani, Majid Montazer, Taiebeh Toliat, Mahnaz Mahmoudi Rad \& Tina Harifi (2017): Preparation of Nano Cationic Liposome as Carrier Membrane for Polyhexamethylene Biguanide Chloride through Various Methods Utilizing Higher Antibacterial Activities with Low Cell Toxicity, Journal of Microencapsulation, DOI: 10.1080/02652048.2017.1296500

To link to this article: http://dx.doi.org/10.1080/02652048.2017.1296500

Accepted author version posted online: 16 Feb 2017.

Submit your article to this journal $\sqsubset$

View related articles

View Crossmark data ¿ 


\section{Preparation of Nano Cationic Liposome as Carrier Membrane for}

\section{Polyhexamethylene Biguanide Chloride through Various Methods}

\section{Utilizing Higher Antibacterial Activities with Low Cell Toxicity}

Elnaz Ahani ${ }^{\mathrm{a}}$, Majid Montazer ${ }^{\mathrm{b} *}$, Taiebeh Toliat $^{\mathrm{c}}$, Mahnaz Mahmoudi Rad ${ }^{\mathrm{d}}$,

Tina Harifi ${ }^{\mathrm{e}}$

${ }^{a}$ Islamic Azad University, Science and Research Branch, Tehran, Iran

${ }^{\mathrm{b}}$ Department of Textile Engineering, Functional Fibrous Structures \& Environmental Enhancement (FFSEE), Amirkabir Nanotechnology Research Institute (ANTRI), Amirkabir University of Technology, Tehran, Iran.

${ }^{c}$ Department of Pharmaceutics, Faculty of Pharmacy, Tehran University of Medical Sciences, Tehran, Iran.

${ }^{\mathrm{d}}$ Skin Research Centre, Shahid Beheshti University of Medical Sciences, Tehran, Iran

${ }^{\mathrm{e}}$ Department of Textile Engineering, Functional Fibrous Structures \& Environmental Enhancement (FFSEE), Amirkabir University of Technology, Tehran, Iran.

*Corresponding author: Dr. Majid Montazer, Associate Professor, Department of Textile Engineering, Functional Fibrous Structures \& Environmental Enhancement (FFSEE), Amirkabir Nanotechnology Research Institute (ANTRI), Amirkabir University of Technology, Tehran, Iran.

Email: tex5mm@aut.ac.ir

Tel: +9821 64542657

Fax: +982166400245 


\title{
Preparation of Nano Cationic Liposome as Carrier Membrane for \\ Polyhexamethylene Biguanide Chloride through Various Methods
}

Utilizing Higher Antibacterial Activities with Low Cell Toxicity

\begin{abstract}
This study suggested successful encapsulation of polyhexamethylene biguanide chloride (PHMB) into nano cationic liposome as a biocompatible antibacterial agent with less cytotoxicity and higher activities. Phosphatidylcholine, cholesterol and stearylamine were used to prepare nano cationic liposome using thin film hydration method along with sonication or homogenizer. Sonication was more effective in PHMB loaded nano cationic liposome preparation with smaller size (34 nm). FTIR, 1H NMR and XRD analyses were used to confirm the encapsulation of PHMB into nano cationic liposome. PHMB inclusion in nano cationic liposome was beneficial for increased antibacterial activity against Staphylococcus aureus and Escherichia coli. PHMB-loaded cationic liposome enables to deliver high concentrations of the antibacterial agent into the infectious cell. The cytotoxicity of PHMB entrapped in positively charged liposome was prominently reduced showing no significant visible detrimental effect on normal primary human skin fibroblast cell lines morphology confirming the effective role of cationic liposome encapsulation. Comparing with PHMB alone, encapsulation of PHMB in nano cationic liposome resulted in significant increase in cell viability from 2.4 to $63 \%$.
\end{abstract}

Keywords: Nano cationic liposome, PHMB, Encapsulation, Antibacterial properties, Cytotoxicity. 
1. Introduction

Polyhexamethylene biguanide (PHMB) is a famous water soluble $(41 \pm 1 \% \mathrm{w} / \mathrm{w}$ at $25^{\circ} \mathrm{C}$ ) cationic antibacterial agent with potential applications in industry, medicine, and wound healing (Abad-Villar et al. 2006, Jeong et al. 2007, Müller et al. 2011, Dilamian et al. 2013, Kapalschinski et al. 2013, Müller et al. 2013, Mashat, 2016). PHMD interaction with negatively charged phosphate groups of phospholipids, altering permeability of the bacterial cellular membrane causing pathogen death is the main mechanism of PHMB antibacterial activity (Wiegand et al. 2013, Napavichayanun et al. 2015). The antiviral efficiency of PHMB against HPV infection and herpes simplex virus has been confirmed (Passic et al. 2010). Moreover, the in vitro activity of PHMB against HIV-1 has been reported (Passic et al. 2010). In spite of these merits, PHMB was found cytotoxic toward mammalian cells causing considerable epithelial damage and inflammation (Krebs et al. 2005). According to European science committee, PHMB is classified as carcinogenic, mutagenic and reprotoxic material and it has been prohibited as a cosmetic ingredient (Bernauer, 2015). Many efforts have been made to introduce variant structures of PHMB with decreased cytotoxicity (Krebs et al. 2005). Decreasing the cytotoxicity of PHMB along with maintaining the antibacterial activity is our main goal in this study. To this end, PHMB was encapsulated into nano cationic liposome.

Liposomes have been widely studied as carriers of various drugs and bioactive materials (Kulkarni et al. 1995, Monshipouri and Rudolph, 1995, Kim et al. 1995, Dufour et al. 1996, Zong et al. 2016). Cationic liposomes with superiority over neutral and anionic ones are effective as non-viral gene carriers in human gene (Yang et al. 2012), drug delivery vehicles, antibacterial agents (Barani et al. 2014, Sehgal and Rogers, 1995), DNA delivery formulation (Woodle et al. 2001), antigens (Bal et al. 
2011), and drug formulations. Dry-film, solvent evaporation (Zhu et al. 2011), ethanol injection (Yang et al. 2012) and double-emulsion are common techniques for synthesis of cationic liposome. Reaction of positively charged cationic liposomes with negatively charged phosphates bacterial exterior membrane cause membrane distortion and subsequent cell death (Mamizuka and Ribeiro 2007, Salvati et al. 2006). Nano cationic liposomes are safe systems in gene therapy and drug delivery which have been used for encapsulation and controlled release of pharmaceuticals (Goldberg et al. 2007, Colas et al. 2007).

Here we tried to study the possibility of PHMB encapsulation into nano cationic liposome to achieve less cytotoxicity along with efficient antibacterial property. Nano cationic liposome loaded with PHMB was prepared using thin film hydration method along with sonication or homogenization. PHMB-loaded cationic liposome enables to deliver high concentrations of the antibacterial agent into S. aureus and E. coli bacteria with less cytotoxic effect on human dermal fibroblasts.

\section{Materials and methods}

\subsection{Materials}

Polyhexamethylene biguanide hydrochloride (PHMB), soybean phosphatidylcholine (SPC, purity: 98\%), stearylamine as cationic surfactant, cholesterol (CHOL, purity > 99\%) and Caso agar were obtained from Applichem (Germany), Lemandou Chemicals (China) and Merck (Germany), respectively. All other organic reagents were purchased from Merck (Germany). Water was purified by Millipore system (18.2, Millipore, USA) filtered through $0.22 \mu \mathrm{m}$ Millipore Millipak®-40 disposable filter unit. 


\subsection{Methods}

2.2.1. Preparation of nano cationic liposome and nano cationic liposome loaded with PHMB

Cationic liposomes were prepared using thin film hydration method (Bangham, 1978). Phosphatidylcholine, cholesterol and stearylamine in the molar ratio of 6:1.5:1 were poured in chloroform $(20 \mathrm{~mL})$ in a $50 \mathrm{~mL}$ round-bottomed flask and vigorously mixed by shaking. The mixture was placed in a rotary vacuum evaporator fitted with an A3S aspirator (Eyela, Tokyo Rikakikai Co. Ltd., Tokyo, Japan) in a circulating bath (SpacN Service, Kolkata, India) and rotated at $150 \mathrm{rpm}$ and $37{ }^{\circ} \mathrm{C}$ to evaporate the solvent. The solvent was removed under vacuum at 20-30 ${ }^{\circ} \mathrm{C}$ and $30-50 \mathrm{rpm}$ with a rotary evaporator. The resultant thin film was dried under vacuum for $1 \mathrm{~h}$ to complete removal of solvent. The dried lecithin film was dispersed in $10 \mathrm{~mL}$ distilled water and stirred at room temperature to complete removal of the lipid layer and formation of lipid vesicles. In this study we abbreviated the prepared cationic liposomes as CLF. The cationic liposome (CLF) was sonicated with a probe-type sonicator (Ultrasonic $\mathrm{UH}-600)$ at $65 \mathrm{~W}$ for $30 \mathrm{~min}$ or homogenizer at $6000 \mathrm{rpm}$ for $30 \mathrm{~min}$ to produce uniform nano cationic liposomes. The resultant nano cationic liposomes were called $\mathrm{CLF}_{\mathrm{S}}$ and $\mathrm{CLF}_{\mathrm{H}}$, depending on the method of nano formation. Thus, here we had three control samples including CLF, CLF $\mathrm{S}_{\mathrm{s}}$ and $\mathrm{CLF}_{\mathrm{H}}$ referring to cationic liposome, nano cationic liposome formed under sonication and nano cationic liposome formed under homogenization. In order to produce liposomes loaded with PHMB, the dried lecithin film was dispersed in $10 \mathrm{~mL}$ PHMB $(0.4 \%)$ and stirred at room temperature to complete removal of the lipid layer and formation of lipid vesicles. This substantially increased the loading of PHMB in liposome. Subsequently, sonication and homogenization were used to prepare nano cationic liposomes loaded with 
PHMB. Thus, here we had three samples named as CLPF, CLPF and $\mathrm{CLPF}_{\mathrm{H}}$, referring to cationic liposome loaded with PHMB, nano cationic liposome loaded with PHMB formed via sonication and nano cationic liposome loaded with PHMB formed under homogenization. Finally all the prepared samples were put into 5-mL freezedrying vials with a fill volume of $2 \mathrm{~mL}$, and rapidly frozen at $-80{ }^{\circ} \mathrm{C}$ in an ultra-cold freezer to be lyophilized. They were put into a freeze-dryer (CHRIST, alpha 2-4 LD, Germany), freezing at $-25^{\circ} \mathrm{C}$ for $24 \mathrm{~h}$ and immediately sealed with rubber caps.

As reported earlier in many published literature (Monteiro et al. 2014), for encapsulation of water soluble bioactive agents (such as PHMB that we used in this study), cholestrol and saturated phospholipids are the most important factors allowing the membrane permeability to be reduced. Cholesterol in combination with saturated phospholipids make liposome membrane stronger. The hydrophobic interactions of cholestrol with membrane lipids forces phospholipid head-groups to shield cholestrol from water. Stabilization and maintenance of the bioactive agent in the core of the liposome is guaranteed by cholesterol. Furthermore, use of saturated lipids provides more liquid phase volume which is appropriate for higher water soluble PHMB encapsulation. Moreover, unsaturated lipids are more prone to physical and chemical deterioration, such as aggregation and peroxidation (Huang et la. 1998). As proposed by Crosasso et al saturated lipids increase the stability and encapsulation efficiency of liposomes (2000).

\subsubsection{PHMB encapsulation efficiency}

$100 \mu \mathrm{g} / \mathrm{mL}$ PHMB solution was prepared and used for recording the maximum absorbance wavelength using UV-visible spectrophotometer $\left(\lambda_{\max }=236 \mathrm{~nm}\right)($ Optizen 2120 UV Plus beam ultraviolet-visible spectrophotometer). Calibration curve was derived for different concentrations of PHMB solution $(5,8,10,16,20,30 \mu \mathrm{g} / \mathrm{mL})$ 
and used for calculating PHMB encapsulation efficiency. By plotting concentration versus absorbance at $236 \mathrm{~nm}$, the concentration of an unknown PHMB solution was determined. The obtained calibration equation is shown in Eq. (1) with R-squared of 0.9966:

$\mathrm{y}=0.0535 \mathrm{x}-0.0042$

Where $\mathrm{y}$ is PHMB concentration $(\mu \mathrm{g} / \mathrm{mL})$ and $\mathrm{x}$ is absorbance at $236 \mathrm{~nm}$.

In a typical procedure for calculating PHMB encapsulation efficiency, $2 \mathrm{~mL}$ of $\mathrm{CLPF}_{\mathrm{S}}$ or $\mathrm{CLPF}_{\mathrm{H}}$ was poured into a filter tube and centrifuged at $23000 \mathrm{rpm}$ and $4{ }^{\circ} \mathrm{C}$ for $1 \mathrm{~h}$. The same procedure was done for $\mathrm{CLF}_{\mathrm{S}}$ or $\mathrm{CLF}_{\mathrm{H}}$ as control samples. The absorbance of the obtained samples was measured at $236 \mathrm{~nm}$ and related to concentration using calibration equation. The encapsulation efficiency was calculated based on Eq. (2), dividing the concentration of PHMB loaded in the liposome $\left(\mathrm{F}_{\mathrm{i}}\right)$ by the initial concentration of the applied PHMB $\left(\mathrm{F}_{\mathrm{t}}\right)$ :

Encapsulation efficiency $(\%)=\mathrm{F}_{\mathrm{i}} / \mathrm{F}_{\mathrm{t}} \times 100$

\subsection{Characterization tests}

Dynamic light scattering (DLS) measurements were employed to characterize the size, size distribution and zeta potential of samples using Malvern Zetasizer (Malvern Instruments, Malvern, U.K.).

In order to obtain the field emission scanning electron microscopic picture, the samples were fixed on an SEM-stub using conductive double sided tape, coated in a vacuum with a thin layer of gold, and examined using a field emission scanning electron microscope (ACC.V, Philips, Poland) equipped with a complete digital computer control system.

In order to investigate Fourier-transform infrared (FT-IR), Proton nuclear magnetic resonance $\left({ }^{1} \mathrm{H} \mathrm{NMR}\right)$ and X-ray diffraction (XRD), the samples were lyophilized. 
Samples were put into 5-mL freeze-drying vials with a fill volume of $2 \mathrm{~mL}$, and rapidly frozen at $-80{ }^{\circ} \mathrm{C}$ in an ultra-cold freezer. They were put into a freeze-dryer (CHRIST, alpha 2-4 LD, Germany), freezing at $-25^{\circ} \mathrm{C}$ for $24 \mathrm{~h}$ and then immediately sealed with rubber caps.

FT-IR spectra were obtained on a Thermo Nicolet Nexus 870 FT-IR ranging from 4000 to $400 \mathrm{~cm}^{-1}$ with $1 \mathrm{~cm}^{-1}$ resolution.

${ }^{1} \mathrm{H}$ NMR spectra for PHMB, CLF and $\mathrm{CLPF}_{\mathrm{S}}$ were separately recorded on a NMR system (DPX 3000MHZ VT). Samples were suspended in DMSO-d6, put into 5-mmwidth NMR sample tubes and then H-NMR spectra were measured at $25^{\circ} \mathrm{C}$. XRD patterns were recorded on a XRD 3003 PTS 1 diffractometer (SEIFERT, Germany) using $\mathrm{CuK} \alpha$ radiation and a scanning rate of $4 \% \mathrm{~min}$ at $40 \mathrm{kV}$ and $30 \mathrm{~mA}$. The divergence and scattering slit was $1^{\circ}$ for $2 \theta$ range of $5-60^{\circ}$.

\subsection{Antibacterial activities}

Both qualitative (agar well diffusion) and quantitative (bacterial killing kinetic) methods were applied for determining the antibacterial efficiency of samples using laboratory strains of Staphylococcus aureus (S. aureus) (ATCC 6538) as a Grampositive bacterium and Escherichia coli (E. coli) (ATCC 8739) as a Gram negative bacterium. The test strains were stored as frozen stocks at $-70{ }^{\circ} \mathrm{C}$ in PBS (phosphate buffered saline) containing $20 \%(\mathrm{v} / \mathrm{v})$ glycerol. Fresh cultures were prepared by inoculating $100 \mathrm{~mL}$ aliquots of the thawed microbial stock suspensions into Caso agar plates and incubated overnight at $35{ }^{\circ} \mathrm{C}$. The bacteria inoculate was prepared by suspending overnight colonies from CASO agar medium in $0.9 \%$ saline. The bacteria inoculate was adjusted at $600 \mathrm{~nm}$ to a cell density equivalent to $0.5 \mathrm{McFarland}$ standard $\left(1.5 \times 10^{8} \mathrm{CFU} / \mathrm{mL}\right)$ before use. 


\subsubsection{Qualitative antibacterial test (Agar-well diffusion)}

The qualitative antibacterial test was carried out based on inhibition zone surrounding the samples where bacteria growth is inhibited. For this purpose, the surface of Petri dishes containing $25 \mathrm{~mL}$ of CASO agar was seeded individually with bacterial suspensions (equivalent to $0.5 \mathrm{McF}$ arland standard, $1.5 \times 10^{8} \mathrm{CFU} / \mathrm{mL}$ ) with a sterile cotton swab. Wells with $7 \mathrm{~mm}$ diameter were created by punching a stainless steel cylinder on the agar plates and removing the agar to form a well. Finally, $80 \mu \mathrm{L}$ aliquots of each prepared sample was placed individually in two wells. The prepared Petri dishes were incubated for $24 \mathrm{~h}$ at $37^{\circ} \mathrm{C}$, and diameters of inhibition zones were determined. In this method, if the bacterial strain is susceptible to the antimicrobial agent, a zone of inhibition appears on the agar plate and if it is resistant to the antimicrobial agent, no zone is evident. The size of inhibition zone is usually related to the level of antimicrobial activity, as a larger zone of inhibition means that the antimicrobial is more potent.

\subsubsection{Quantitative antibacterial test}

The quantitative antibacterial test was carried out according to AATCC 100-2004. For this purpose, each sample was individually poured in a sterile test tube and inoculated with bacterial suspension at a final concentration of $10^{5} \mathrm{CFU} / \mathrm{mL} .1 \mathrm{~mL}$ aliquot was removed at different intervals of $0,1,3$, and $6 \mathrm{~h}$ and added to $9 \mathrm{~mL}$ of neutralizing solution containing $1 \%$ sodium thiosulphate $\left(\mathrm{Na}_{2} \mathrm{~S}_{2} \mathrm{O}_{3}\right), 0.6 \%$ sodium thioglycolate $\left(\mathrm{H}_{\mathrm{S}} \mathrm{CH}_{2} \mathrm{COONa}\right)$, and $0.1 \%$ polysorbate 80 . The antibacterial activity of samples at different times was assessed by counting the number of colony units based on Eq. (3):

Bacterial reduction $\%=\left(\mathrm{N}_{0}-\mathrm{N}\right) / \mathrm{N}_{0} \times 100$

Where $\mathrm{N}$ is the number of bacteria recovered from the samples at any defined time and $\mathrm{N}_{0}$ is the number of bacteria recovered from the samples at zero contact time. 


\subsection{Cytotoxicity assay}

Normal primary human skin fibroblast was cultured in growth medium (Dulbecco's Modified Eagle's Medium DMEM) (1X) (Biochrom, Berlin, Germany)+2 mM GlutMAX ${ }^{\mathrm{TM}}\left(\mathrm{Gibco}^{\mathrm{TM}}\right)$ supplemented with $10 \%$ fetal calf serum (FCS) and incubated at $37{ }^{\circ} \mathrm{C}$ in humidified $5 \% \mathrm{CO}_{2} / 95 \%$ air. 96-well plates were used for all the experiments. Cells from passage 3 were seeded in each well and incubated for 2 days. Thereafter, samples including PHMB, nano cationic liposome, and nano cationic liposome loaded with PHMB were added to $2 \mathrm{~mL}$ sterile PBS (buffer phosphate saline) for $24 \mathrm{~h}$ at $37{ }^{\circ} \mathrm{C}$. The cultured medium with leaching substance was added to the cultured cells and incubated for $24 \mathrm{~h}$. After incubation, the samples were investigated by optical microscopic examinations. The cells were reincubated for a further $24 \mathrm{~h}$ in fresh medium and then tested with 3-(4, 5-dimethylthiazol-2-yl)-2, 5diphenyltetrazolium bromide (MTT) assay. A Tecan SunriseTM microplate reader at $492 \mathrm{~nm}$ was used to measure the absorbance. Experiments were performed four times and the obtained results were recorded as percentage absorbance relative to control cells. The cytotoxicity results were used to calculate percentage relative cell viability after incubation with the samples using Eq. (4):

Cell Viability $\%=($ abs sample $/$ abs control $) \times 100$

Where $a b s_{\text {sample }}$ and $a b s_{\text {control }}$ are the absorbance of well containing samples and control. 


\section{Results and discussions}

\subsection{Particle size and zeta potential}

As indicated in Table 1, both homogenization and sonication decreased the average particle size of cationic liposome (CLF) from 1018.1 $\pm 0.2(\mathrm{~nm})$ to $301.3 \pm 0.1(\mathrm{~nm})$ and 43.2 $\pm 0.2(\mathrm{~nm})$, respectively. Thus, sonication was more effective in size reduction, producing nano cationic liposome. An increase in average particle size to $1042.7 \pm 0.1$ (nm) for liposome loaded with PHMB (CLPF) indicated the presence of PHMB in the liposome. $\mathrm{CLPF}_{\mathrm{S}}$ possessed the smallest particle size $(56.8 \pm 0.1(\mathrm{~nm}))$ and regarded as the optimum sample for further investigation.

The distribution of particle size was further analyzed by PDI (poly dispersity index). As included in Table 1, while the PDI of CLF sample without sonication or homogenization was high $(1.000 \pm 0.001)$, this index has been decreased to $0.140 \pm 0.003$ and $0.442 \pm 0.002$ for $\mathrm{CLF}_{\mathrm{S}}$ and $\mathrm{CLF}_{\mathrm{H}}$ samples, indicating the positive effect of sonication and homogenization on uniform distribution of particle size.

The zeta potential depends on the charge density of the cationic component at the surface of the liposomes. Positive zeta potential of all samples is due to stearylamine cationic agent used in the preparation process (Zschornig, 1999).

Generally, the stability of liposome can be controlled by optimizing the size distribution, $\mathrm{pH}$, ionic strength, and addition of antioxidants and chelating agents. There are physical and chemical stability importance. Hydrolysis of the ester bonds linking the fatty acids to the glycerol backbone and peroxidation of unsaturated acyl chains are the possible chemical degradation reactions (Yadav et al. 2011). In our case of study, saturated lipids were used which are more chemically stable. Aggregation/flocculation and fusion/coalescence may affect the physical stability of liposomes. Repulsive interaction between liposome vesicles form stable liposome 
suspensions (Yadav et al. 2011). In our study electrostatic repulsion arose from positive charge of cationic liposomes. Here, in the preparation procedure no electrolyte such as $\mathrm{NaCl}$ was applied. Thus, ionic strength was not changed. As evidenced by our DLS data, polydispersity index of nano liposomes prepared after sonication (as the optimum sample) was low $(0.140 \pm 0.003)$ indicating the homogenous size distribution. Moreover, stability of the prepared nano liposomes is clear from the SEM picture shown in Figure 4.

It is worth noting that in 1984 Crommelin has done a study about the effect of lipid composition and ionic strength on the physical stability of liposomes. He prepared positively charged liposomes with the same lipid composition as ours and used $\mathrm{NaCl}$ solution with variable ionic strength $(2-150 \mathrm{mM})$. According to the results, no aggregation was achieved in low or high ionic strength due to high electrostatic repulsive interactions and hydration forces, respectively (Crommelin, 1984).

\section{Table 1}

\subsection{Encapsulation efficiency}

PHMB as a hydrophilic polymer freely dissolves in water and locates in the interior aqueous cavity of liposome (Silva et al. 2008). As shown in Table 1, the encapsulation efficiency of CLPF with average particle size of $1042.7 \pm 0.1 \mathrm{~nm}$ was $71.0 \pm 0.1$ which was decreased to $53.6 \pm 0.2$ for nano cationic liposome loaded with PHMB $\left(\mathrm{CLPF}_{\mathrm{S}}\right)$ with particle size of $56.8 \pm 0.1 \mathrm{~nm}$. The decreased encapsulation efficiency was due to the lower liquid phase volume of cationic liposome in nano size (Ducat et al. 2014, Maestrelli et al. 2006). In spite of the decreased loading efficiency, nano cationic liposome was favorable for PHMB encapsulation due to its high surface area. 


\subsection{FTIR analysis}

According to Figure 1 (a), absorbance bands at 1567.9, 1740.9 and $2925.4 \mathrm{~cm}^{-1}$ assigned to $\mathrm{NH}_{2}, \mathrm{C}=\mathrm{O}$ and $\mathrm{C}-\mathrm{H}$ aliphatic (Figure 1(b)) are characteristic bands of cationic liposome $\left(\mathrm{CLF}_{\mathrm{S}}\right)$. Moreover, the characteristic absorbance peaks for PHMB are observed at $1637.4,2929.5$ and $3421.3 \mathrm{~cm}^{-1}$ (Figure (1b)) attributing to $\mathrm{C}=\mathrm{N}$ stretching, $\mathrm{C}-\mathrm{H}$ aliphatic and $\mathrm{N}-\mathrm{H}$ stretching vibration, respectively. Furthermore, the prominent characteristic band of PHMB due to $\mathrm{NH}_{2}{ }^{+}$band vibration is detected at $1549.0 \mathrm{~cm}^{-1}$. In comparison to FT-IR spectrum of cationic liposome (Figure 1 (a)), absorbance bands at 1641.9 and $1556.3 \mathrm{~cm}^{-1}$ can be seen for $\mathrm{CLPF}_{\mathrm{S}}$ sample (Figure 1 (c)) arising from $\mathrm{C}=\mathrm{N}$ functional group and $\mathrm{NH}_{2}{ }^{+}$groups relating to $\mathrm{PHMB}$ loading of cationic liposome. Hence, successful encapsulation of PHMB in CLPF, has been proved (Zhang et al. 1999). Detailed band assignments of CLF, PHMB and $\mathrm{CLPF}_{\mathrm{S}}$ samples are summarized in Table 2.

Figure

Table 2

\subsection{H NMR spectroscopy}

Using ${ }^{1} \mathrm{H}$ NMR in addition to FT-IR helped to reconfirm the successful loading of PHMB in cationic liposome. The ${ }^{1} \mathrm{H}$ NMR spectral data were recorded in $\mathrm{CDCl}_{3}$ with the chemical shifts expressed in ppm downfield from tetramethylsilane. For comparison, the spectra of free PHMB and $\mathrm{CLF}_{\mathrm{S}}$ are shown in Figure $2(\mathrm{a}, \mathrm{b})$. The ${ }^{1} \mathrm{H}$ NMR spectrum of PHMB loaded into nano cationic liposome is also presented in Figure 2 (c). As indicated in Figure 2 (a), three different signals are observed for PHMB at 6.00, 4.00 and 1.50-2.00 ppm relating to imides $\left(\mathrm{C}=\mathrm{NH}_{2}\right)$, the second amine $\left(\mathrm{NH}-\mathrm{CH}_{2}\right)$ and hydrocarbon chain $\left(\mathrm{CH}_{2}-\mathrm{CH}_{2}\right)$ (Eriksson 1987). Up-field shift of all 
signals as compared to ${ }^{1} \mathrm{H}$ NMR spectrum of free PHMB is observed for $\mathrm{CLPF}_{\mathrm{S}}$ sample due to $\mathrm{C}=\mathrm{NH}_{2}$ coordination of $\mathrm{PHMB}$ (Figure 2(c)).

Figure 2

\subsection{X-ray diffraction}

Presence of PHMB in cationic liposome was further confirmed by studying the XRD patterns of PHMB, CLF and $\mathrm{CLPF}_{\mathrm{S}}$ samples (Figure 3). In order to distinguish between the spectra, second order derivative of each spectrum is also shown in Figure 3. Two peaks were detected in second order derivative spectrum of PHMB at $2 \theta=6-7^{\circ}$ (Figure 3 (a)). In comparison, nano cationic liposome possessed one sharp peak at $2 \theta=6^{\circ}$. PHMB encapsulation in nano cationic liposome caused changes in second order derivative spectrum of PHMB at $2 \theta=6-7^{\circ}$, as the XRD spectrum of CLPF more resembled the $\mathrm{CLF}_{\mathrm{S}}$ spectrum with one sharp peak at $2 \theta=6.8^{\circ}$.

The crystal size of PHMB, CLF and $\mathrm{CLPF}_{\mathrm{S}}$ samples were calculated using the Scherer's equation (Eq. (4)):

Crystal size $=0.9 \lambda / \beta \cos (\theta)$

Where $\lambda$ is the wavelength of $\mathrm{CuK} \alpha$ radiation applied $\left(\lambda=1.5418 \mathrm{~A}^{\circ}\right), \theta$ is the Bragg's angle of diffraction and $\beta$ is the full-width at half maximum intensity of the peak observed (converted to radian). An increase in crystal size of $\operatorname{CLPF}_{\mathrm{S}}(0.77 \mathrm{~nm})$ comparing with crystal size of PHMB $(0.66 \mathrm{~nm})$ and $\mathrm{CLF}_{\mathrm{S}}(0.069 \mathrm{~nm})$ indicates the presence of PHMB in the nano cationic liposome.

\subsection{SEM images}

Figure 3

The optimum sample $\left(\mathrm{CLPF}_{\mathrm{S}}\right)$ was analyzed by FESEM to estimate the size of the prepared encapsulated liposome. As shown in Figure 4, nano cationic liposomes with mean vesicle size of $34 \mathrm{~nm}$ were successfully prepared. Well-dispersed vesicles were in spherical shape and had uniform distribution. Thus, FESEM image was a further 
confirm to the successful role of sonication in preparing nano cationic liposomes loaded with PHMB. The obtained result was in accordance with DLS and PDI data.

Figure 4.

\subsection{Antibacterial properties}

\subsubsection{Qualitative study}

The most effective antibacterial agent against both Gram-positive and Gram-negative bacteria was PHMB possessing the greatest inhibition zone diameter due to high binding affinity to the negatively charged cell walls and membranes of bacteria, causing membrane disruption and cell death (Table 3) (Kawa et al. 2009). Although a smaller mean inhibition zone diameter was found for nano cationic liposome $\left(\mathrm{CLF}_{\mathrm{S}}\right)$, cationic liposome loaded with PHMB $\left(\mathrm{CLPF}_{\mathrm{S}}\right)$ was effective in penetrating into the bacterial cytoplasmic membrane and its destruction with $24.00 \pm 0.1$ and $20.00 \pm 0.2$ mm mean inhibition zone diameter against S. aureus and E. coli. Thus, the potential efficiency of cationic liposome containing PHMB in delivering the bactericide to the target was successfully confirmed.

As indicated by qualitative antibacterial test results, the greatest inhibition zone belonged to the PHMB sample. However, PHMB was found cytotoxic toward mammalian cells causing considerable epithelial damage and inflammation (Krebs et al. 2005). Thus, here we tried to study the possibility of PHMB encapsulation into nano cationic liposome to achieve less cytotoxicity along with efficient antibacterial property. As confirmed by cytotoxicity test (section 3.8), the cytotoxicity of PHMB entrapped in positively charged liposome was prominently reduced. Thus, the resultant $\mathrm{CLPF}_{\mathrm{S}}$ sample possessed the optimum antibacterial efficiency along with reduced cytotoxicity. 


\section{Table 3}

\subsubsection{Quantitative study}

Reduction percentage of $S$. aureus and E. coli for nano cationic liposome formed under sonication $\left(\mathrm{CLF}_{\mathrm{s}}\right)$ was $94.90 \pm 0.01$ and $90.2 \pm 0.005(\%)$ after $1 \mathrm{~h}$ incubation. Increased incubation time resulted in higher antibacterial activities reaching to $97.0 \pm 0.005$ (after 3 h), 99.99 \pm 0.01 (after 6 h), and 96.70 \pm 0.01 (after 3h), 99.99 \pm 0.01 (after 6 h) against $S$. aureus and E. coli, respectively.

In comparison, PHMB loading into nano cationic liposome formed via sonication $\left(\mathrm{CLPF}_{\mathrm{S}}\right)$ was successful in complete bacteria killing after 15 min incubation obtaining $99.99 \pm 0.01$ antibacterial efficiencies against both $S$. aureus and $E$. coli. Thus, cationic liposome was effective in target delivery of PHMB as antibacterial agent into the bacteria cell. The antibacterial mechanism is related to the cationic liposome attack to the bacterial cell wall and PHMB penetration into the cytoplasmic membrane causing subsequent cell death. Strong affinity of cationic liposome as effective carrier membrane targeting E.coli and S.aureus has been known. (Kim et al. 1999, Brunner et al. 2006). Moreover, transfection efficiency, penetration and fluidity of membrane were increased due to the presence of cholesterol in cationic liposome (Barani et al. 2011, Webb et al. 1995).

\subsection{Cytotoxicity tests}

Under exposure to toxic agents the first visible change is observed in cell shape rather than any morphological changes in metabolism or proliferation (Brunner et al. 2006). Thus, cytotoxicity test was performed to evaluate harmful effects of PHMB on dermal fibroblast through monitoring any changes in optical microscopy after three days (Figure 5). Moreover, percentage of cell viability of samples comparing with control was quantitatively evaluated (Figure 6). Figure 5 (a) shows normal growing spindle- 
shaped cells. After incubation with PHMB (Figure 5 (b)), complete cell destruction has been occurred in almost all cells, indicating the harmful toxic effects of PHMB. Morphology of cultured human dermal fibroblast in presence of PHMB differs from optical microscopic picture of control containing normal growing spindle shaped cells (Figure $5(\mathrm{a}, \mathrm{b})$ ). Comparing with the control having a cell viability of $100 \%$ (Figure 6), the average cell viability over PHMB after $24 \mathrm{~h}$ of incubation was $2.4 \%$, which confirms the harmful toxic effects of PHMB (Figure 6). In comparison, nano cationic liposome (Figure 5 (c)) possessed normal cultured human dermal fibroblast with similar morphology to control, indicating minimum harmful toxic effect. This was also confirmed by the average cell viability of over $69 \%$ for nano cationic liposome $\left(\mathrm{CLF}_{\mathrm{S}}\right)$, indicating almost good biocompatibility properties (Figure 6).

Comparing with PHMB alone, encapsulation of $\mathrm{PHMB}$ in nano cationic liposome resulted in significant increase in cell viability from 2.4 to $63 \%$ for CLPF $_{\mathrm{S}}$ (Figure 6). Thus, comparing with PHMB alone, although some cells underwent morphological changes against nano cationic liposome loaded with PHMB, most of them are viable retaining their initial spindle shape (Figure $5(d)$ ). Therefore, no considerable adverse effect on human skin was found for nano cationic liposome loaded with PHMB. Thus, the cytotoxicity of PHMB entrapped in positively charged liposome was prominently reduced, confirming the effective role of cationic liposome encapsulation (Zhen et al. 2009).

Figure 5

Figure 6 


\section{Conclusion}

To sum up, successful encapsulation of PHMB into nano cationic liposome was carried out using thin film hydration method along with sonication or homogenization. This was confirmed through different characterization tests namely FTIR, ${ }^{1} \mathrm{H}$ NMR and XRD. The prepared PHMB loaded nano cationic liposome with $34 \mathrm{~nm}$ diameter was beneficial as a new carrier membrane with enhanced antibacterial activity against $S$. aureus and E. coli and reduced cytotoxicity effects on cultured human dermal fibroblasts. PHMB and nano cationic liposome with synergistic effect had the potential to be introduced as an innovative system for target delivery of antibacterial agent to infectious sites with no detrimental cytotoxic effects.

\section{Disclosure of interest}

The authors report no conflicts of interest

\section{References}

Abad-Villar, E.M., Etter, S.F., Thiel, M.A., Hauser, P. C. 2006. Determination of chlorhexidine digluconate and polyhexamethylene biguanide in eye drops by capillary electrophoresis with contactless conductivity detection. Analytica Chimica Acta. 56, 133-137.

Bal, S.M., Hortensius, S., Ding, Zh, Jiskoot, W., Bouwstra, J.A. 2011. Coencapsulation of antigen and Toll-like receptor ligand in cationic liposomes affects the quality of the immune response in mice after intradermal vaccination. Vaccine. 29, $1045-1052$.

Bangham, A. 1978. Properties and uses of lipid vesicles: an overview. Annals of the New York Academy of Sciences, 308, 2-7. 
Barani, H., Montezer, M., Samadi, N., Toliyat, T. 2011. Nano silver entrapped in phospholipids membrane: synthesis, characteristics and antibacterial kinetics. Molecular Membrane Biology. 28, 206-215.

Barani, H., Montazer, M., Braun, H.G., Dutschk, V. 2014. Stability of colloidal silver nanoparticles trapped in lipid bilayer: effect of lecithin concentration and applied temperature. IET Nanobiotechnology. 8, 282-289.

Bernauer, U. 2015. Opinion of the scientific committee on consumer safety (SCCS)2nd Revision of the safety of the use of poly(hexamethylene) biguanide hydrochloride or polyaminopropyl biguanide (PHMB) in cosmetic products, Regulatory Toxicology and Pharmacology, 73, 885-886.

Brunner, T.J., Wick, P., Manser, P. 2006. In vitro cytotoxicity of oxide nanoparticles: comparison to asbestos, silica, and the effect of particle solubility. Environmental Science and Technology. 40, 4374-4381.

Colas, J. Ch, Shi, W., Rao, V.S.N.M, Mozafari, M.R., Singh, H. 2007. Microscopical investigations of nisin-loaded nanoliposomes prepared by Mozafari method and their bacterial targeting. Micron. 38, 841-847.

Crommelin, D.J.A. 1984. Influence of lipid composition and ionic strength on the physical stability of liposomes. Journal of Pharmaceutical Sciences, 73, 1559-1562.

Crosasso, P., Ceruti, M., a Brusa, P., Arpicco, S., Dosio, F., Cattel, L. 2000. Preparation, characterization and properties of sterically stabilized paclitaxelcontaining liposomes. Journal of Controlled Release, 63, 19-30.

Dilamian, M., Montazer, M., Masoumi, J. 2013. Antimicrobial electrospun membranes of chitosan/poly (ethylene oxide) incorporating poly (hexamethylene biguanide) hydrochloride. Carbohydrate Polymers. 94, 364-371. 
Ducat, E., Deprez, J., Gillet, A., Noël, A., Evrard, B., Peulen, O., Piel, G. 2011. Nuclear delivery of a therapeutic peptide by long circulating $\mathrm{pH}$-sensitive liposomes: benefits over classical vesicles. International Journal of Pharmaceutics, 420, 319332.

Dufour, P. J., Vuillemard, C., Laloy, E., Simard, R. E. 1996. Characterization of enzyme immobilization in liposomes prepared from proliposomes. Journal of Microencapsulation: Micro and Nano Carriers. 13, 185-194.

Eriksson, L.E.G. 1987. Interaction of charged amphiphilic drugs with phosphatidylcholine vesicles studied by NMR. Biophysical Chemistry. 26, 9-18.

Goldberg, M., Langer, R., Jiac, X. 2007. Nanostructured materials for applications in drug delivery and tissue engineering. Journal of biomaterials Science: Polymer Edition. 18, 241-268.

Huang, Y.Y., Chung, T.W., Wu, C.I. 1998. Effect of saturated/unsaturated phosphatidylcholine ratio on the stability of liposome-encapsulated hemoglobin. International Journal of Pharmaceutics, 172, 161-167.

Jeong, H.J, Lee, S.J., Kim, J.H., Xuan, Y.H., Lee, K.H., Park, S.K., Choi, S.H., Chung, D.I., Kong, H.H., Ock, M.S., Yu, H.S. 2007. Acanthamoeba: keratopathogenicity of isolates from domestic tap water in Korea. Experimental Parasitology, 117, 357-367.

Kapalschinski N, Seipp HM, Onderdonk AB, Goertz, O., Daigeler, A., Lahmer, A., Lehnhardt, M., Hirsch, T. 2013. Albumin reduces the antibacterial activity of polyhexanide-biguanide-based antiseptics against Staphylococcus aureus and MRSA. Burns. 39, 1221-1225. 
Kawa ZD, Jacha AD, Gubernator J, Doroszkiewicz, W., Kozubek, A. 2009. In vitro antimicrobial of liposomal meropenem against Pseudomonas aeruginosa strains. International Journal of Pharmaceutics, 367, 211-219.

Kim, C. K., Han, J. H. 1995. Lymphatic delivery and pharmacokinetics of methotrexate after intramuscular injection of differently charged liposome-entrapped methotrexate to rats. Journal of Microencapsulation: Micro and Nano Carriers. 12, 437-446.

Kim, H.J., Gias, E.L.M, Jones, M.N. 1999. The adsorption of cationic liposomes to Staphylococcus aureus biofilms. Colloids and Surfaces A. 149, 561-570.

Krebs FC, Miller SR, Ferguson, M.L., Labib, M., Rando, R.F., Wigdahl, B. 2005. Polybiguanides, particularly polyethylene hexamethylene biguanide, have activity against human immunodeficiency virus type 1. Biomedicine \& Pharmacotherapy. 59, 438-445.

Kulkarni, S. B., Betageri, G. V., Singh, M. 1995. Factors affecting microencapsulation of drugs in liposomes. Journal of Microencapsulation: Micro and Nano Carriers. 12, 229-246.

Maestrelli F, Gonzalez-Rodriguez ML, Rabasco AM, Mura, P. 2006. Effect of preparation technique on the properties of liposomes encapsulating ketoprofencyclodextrin complexes aimed for transdermal delivery. International Journal of Pharmaceutics, 312, 53-60.

Mamizuka, E.M., Ribeiro, A.M.C. 2007. Cationic liposomes as antimicrobial agents. In: A. Méndez-Vilas, A. Ed. Communicating current research and educational topics and trends in applied microbiology. Spain: Formatex, 636-647.

Mashat, B.H. (2016). Polyhexamethylene biguanide hydrochloride: Features and applications. British Journal of Environmental Sciences, 4, 49-55. 
Monshipouri, M. Rudolph, A.S. 1995. Liposome encapsulated alginate: controlled hydrogel particle formation and release. Journal of Microencapsulation: Micro and Nano Carriers. 12, 117-127.

Monteiro, N., Martins, A., Reis, R.L., Neves, N.M. 2014. Liposomes in tissue engineering and regenerative medicine. Journal of the Royal Society Interface, 11, 124.

Müller, G., Kramer, A., Schmitt, J., Harden, D., Koburger, T. 2011. Reduced cytotoxicity of polyhexamethylene biguanide hydrochloride (PHMB) by egg phosphatidylcholine while maintaining antimicrobial efficacy. Chemico-Biological Interactions, 190, 171-178.

Müller, G., Koburger, T., Kramer, A. 2013. Interaction of polyhexamethylene biguanide hydrochloride (PHMB) with phosphatidylcholine containing o/w emulsion and consequences for microbicidal efficacy and cytotoxicity. Chemico-Biological Interactions. 201, 58-64.

Napavichayanun, S.P., Amornsudthiwat, P., Pienpinijtham, P., Aramwita, P. 2015. Interaction and effectiveness of antimicrobials along with healing-promoting agents in a novel biocellulose wound dressing. Materials Science and Engineering C. 2015; 5, 95-104.

Passic, S.R., Ferguson, M.L., Catalone, B.J., Kish-Catalone, T., Kholodovych, V., Zhu, W., Welsh, W., Rando, R., Howett, M.K., Wigdahl, B., Labib, M., Krebs, F.C. 2010. Structure-activity relationships of polybiguanides with activity against human immunodeficiency virus type 1. Biomedicine \& Pharmacotherapy. 64, 723-732.

Salvati, A., Ciani, L., Ristori, S., Martini, G., Masi, A., Arcangeli, A. 2006. Physicochemical characterization and transfection efficacy of cationic liposomes containing the pEGFP plasmid. Biophysicalal. Chemistry. 121, 21-29. 
Sehgal, S., Rogers, J. A. 1995. Polymer-coated liposomes: Improved liposome stability and release of cytosine arabinoside (Ara-C). Journal of Microencapsulation: Micro and Nano Carriers. 12, 37-47.

Silva, R., Little, C., Ferreira, H., Cavaco-Paulo, A. 2008. Incorporation of peptides in phospholipid aggregates using ultrasound. Ultrasonics Sonochemistry. 15, 1026-1032. Webb, M.S., Wheeler, J.J., Bally, M.B., Mayer, L. D. 1995. The cationic lipid stearylamine reduces the permeability of the cationic drugs verapamil and prochlorperazine to lipid bilayers: implications for drug delivery. Biochimica et Biophysica Acta. 1238, 147-155.

Wiegand C, Bauer M, Hipler U Ch, Fischer, D. 2013. Poly (ethyleneimines) in dermal applications: Biocompatibility and antimicrobial effects. International Journal of Pharmaceutics, 456, 165-174.

Woodle, M.C., Scaria, P., Curr, O. 2001. Cationic liposomes and nucleic acids. Colloid Interface Science, 6, 78-84.

Yadav, A.V., Murthy, M.S., Shete, A.S., Sfurti, S. 2011. Stability aspects of liposomes. Indian Journal of Pharmaceutical Education and Research, 45, 402-413. Yang, Sh., Chen, J., Zhao, D., Han, D., Chen, X. 2012. Comparative study on preparative methods of DC-Chol/DOPE liposomes and formulation optimization by determining encapsulation efficiency. International Journal of Pharmaceutics, 434, 155-160.

Zhang, Y., Jiang, J., Chen, Y. 1999. Synthesis and antimicrobial activity of polymeric guanidine and biguanidine salts. Polymer. 40, 6189-6198.

Zheng, X., Lu, J., Deng, L., Yang, X., Jianming, C. 2009. Preparation and characterization of magnetic cationic liposome in gene delivery. International Journal of Pharmaceutics. 366, 211-217. 
Zhu, S.X.L., Dong, Z., Wang, X. 2011. Effects of poly (lactic-co-glycolic acid) on preparation and characteristics of plasmid DNA-loaded solid lipid nanoparticles. IET Nanobiotechnology. 5, 79-85.

Zong, W., Hu, Y., Su, Y., Luo, N., Zhang, X., Li, Q., Han, X., 2016. Polydopamine-

coated liposomes as $\mathrm{pH}$-sensitive anticancer drug carriers. Journal of Microencapsulation: Micro and Nano Carriers. 33, 257-262.

\section{Tables and figures caption}

Table 1. Particle size (nm), poly dispersity index (PDI), positive zeta potential (mV) and encapsulation efficiency (EE \%) of different samples. Data are the mean of three independent analyses \pm S.D.

Table 2. Bands assignments of $\mathrm{CLF}_{\mathrm{S}}$, PHMB and $\mathrm{CLPF}_{\mathrm{S}}$ samples.

Table 3. Mean value of inhibition zone diameter $(\mathrm{mm})$ of different samples. Data are the mean of three independent analyses \pm S.D $(\mathrm{mm})$.

Figure 1. FTIR spectra of (a) nano cationic liposome formed via sonication $\left(\mathrm{CLF}_{\mathrm{S}}\right)$, (b) PHMB, (c) nano cationic liposome loaded with PHMB formed via sonication $\left(\mathrm{CLPF}_{\mathrm{S}}\right)$.

Figure 2. 1H NMR spectra of (a) PHMB (insert is PHMB structure), (b) nano cationic liposome formed via sonication $\left(\mathrm{CLF}_{\mathrm{S}}\right)$ and (c) nano cationic liposome loaded with PHMB formed via sonication $\left(\mathrm{CLPF}_{\mathrm{S}}\right)$.

Figure 3. Smoothed and second derivatives of X-ray diffraction patterns: (a) PHMB, (b) nano cationic liposome formed via sonication $\left(\mathrm{CLF}_{\mathrm{S}}\right)$, and (c) nano cationic liposome loaded with PHMB formed via sonication $\left(\mathrm{CLPF}_{\mathrm{S}}\right)$.

Figure 4. SEM image of nano cationic liposome loaded with PHMB formed via sonication $\left(\mathrm{CLPF}_{\mathrm{S}}\right)$ at $50000 \times$ magnification. 
Figure 5. Photograph of dermal fibroblast cells. (a) control sample showing normal growing spindle-shaped cells, (b) complete cell destruction indicating the harmful toxic effects of PHMB, (c) nano cationic liposome formed via sonication $\left(\mathrm{CLF}_{\mathrm{S}}\right)$ with normal cultured human dermal fibroblast similar to control, and (d) nano cationic liposome loaded with PHMB formed via sonication $\left(\mathrm{CLPF}_{\mathrm{S}}\right)$ with most viable cells retaining the initial spindle shape.

Figure 6. Cell viability of control, PHMB, nano cationic liposome formed via sonication $\left(\mathrm{CLF}_{\mathrm{S}}\right)$, and nano cationic liposome loaded with PHMB formed via sonication $\left(\mathrm{CLPF}_{\mathrm{S}}\right)$. 
Table 1. Particle size (nm), poly dispersity index (PDI), positive zeta potential (mV) and encapsulation efficiency (EE \%) of different samples. Data are the mean of three independent analyses \pm S.D.

\begin{tabular}{|c|c|c|c|c|}
\hline Sample $^{*}$ & $\begin{array}{c}\text { Particle size } \\
(\mathrm{nm})\end{array}$ & PDI & Zeta potential $(\mathrm{mV})$ & $\mathrm{EE}(\%)^{* *}$ \\
\hline CLF & $1018.1 \pm 0.2$ & $0.991 \pm 0.001$ & $+50.2 \pm 0.1$ & $-\cdots--$ \\
\hline $\mathrm{CLF}_{\mathrm{H}}$ & $301.3 \pm 0.1$ & $0.442 \pm 0.002$ & $+74.0 \pm 0.1$ & ---. \\
\hline $\mathrm{CLF}_{\mathrm{S}}$ & $43.2 \pm 0.2$ & $0.140 \pm 0.003$ & $+39.9 \pm 0.08$ & ---- \\
\hline CLPF & $1042.7 \pm 0.1$ & $1.000 \pm 0.001$ & $+30.1 \pm 0.2$ & $71.0 \pm 0.1$ \\
\hline $\mathrm{CLPF}_{\mathrm{H}}$ & $348.4 \pm 0.2$ & $0.493 \pm 0.002$ & $+33.4 \pm 0.2$ & \\
\hline $\mathrm{CLPF}_{\mathrm{S}}$ & $56.8 \pm 0.1$ & $0.176 \pm 0.001$ & $+36.3 \pm 0.3$ & \\
\hline
\end{tabular}

"CLF: cationic liposome, CLF $_{\mathrm{H}}$ : nano cationic liposome formed under homogenization, $\mathrm{CLF}_{\mathrm{S}}$ : nano cationic liposome formed under sonication, CLPF: cationic liposome loaded with PHMB, CLPF ${ }_{\mathrm{H}}$ : nano cationic liposome loaded with PHMB formed under homogenization and CLPF : nano cationic liposome loaded with PHMB formed via sonication.

${ }^{* *} \mathrm{EE} \%$ is percentage of PHMB encapsulation efficiency calculated by dividing the concentration of PHMB loaded in the liposome $\left(\mathrm{F}_{\mathrm{i}}, \mu \mathrm{g} / \mathrm{mL}\right)$ by the initial concentration of the applied PHMB $\left(\mathrm{F}_{\mathrm{t}}\right.$, $\mu \mathrm{g} / \mathrm{mL})$. 
Table 2. Bands assignments of $\mathrm{CLF}_{\mathrm{S}}$, PHMB and $\mathrm{CLPF}_{\mathrm{S}}$ samples.

\begin{tabular}{|c|c|c|}
\hline Sample $^{*}$ & $\begin{array}{c}\text { Specific functional } \\
\text { Groups }\end{array}$ & $\begin{array}{c}\text { Observed frequency } \\
\text { vibration }\left(\mathrm{cm}^{-1}\right)\end{array}$ \\
\hline \multirow{3}{*}{$\mathrm{CLF}_{\mathrm{S}}$} & $\mathrm{NH}_{2}$ & 1567.9 \\
\hline & $\mathrm{C}=\mathrm{O}$ & 1740.9 \\
\hline & C-H aliphatic & 2925.4 \\
\hline \multirow[t]{4}{*}{ PHMB } & $\mathrm{NH}_{2}$ bending & 1549.0 \\
\hline & $\mathrm{C}=\mathrm{N}$ stretching & 1637.4 \\
\hline & C-H aliphatic & 2929.5 \\
\hline & $\mathrm{N}-\mathrm{H}$ stretching & 34 \\
\hline \multirow[t]{4}{*}{$\mathrm{CLPF}_{\mathrm{S}}$} & $\mathrm{NH}_{2}$ bending & \\
\hline & $\mathrm{C}=\mathrm{N}$ stretching & \\
\hline & $\mathrm{C}=\mathrm{O}$ & 1740.0 \\
\hline & C-H aliphatic & 292 \\
\hline
\end{tabular}

"CLFs: nano cationic liposome formed under sonication, PHMB: polyhexamethylene biguanide chloride and $\mathrm{CLPF}_{\mathrm{S}}$ : nano cationic liposome loaded with PHMB formed via sonication.

Table 3. Mean value of inhibition zone diameter $(\mathrm{mm})$ of different samples. Data are the mean of three independent analyses \pm S.D $(\mathrm{mm})$.

\begin{tabular}{ccc}
\hline Sample $^{*}$ & S. aureus & E.coli \\
\hline PHMB & $25.00 \pm 0.1$ & $22.00 \pm 0.1$ \\
$\mathrm{CLPF}_{\mathrm{S}}$ & $24.00 \pm 0.1$ & $20.00 \pm 0.2$ \\
$\mathrm{CLF}_{\mathrm{S}}$ & $20.00 \pm 0.2$ & $19.00 \pm 0.2$
\end{tabular}

PHMB: polyhexamethylene biguanide chloride, $\mathrm{CLPF}_{\mathrm{S}}$ : nano cationic liposome loaded with PHMB formed via sonication and $\mathrm{CLF}_{\mathrm{S}}$ : nano cationic liposome formed under sonication. 


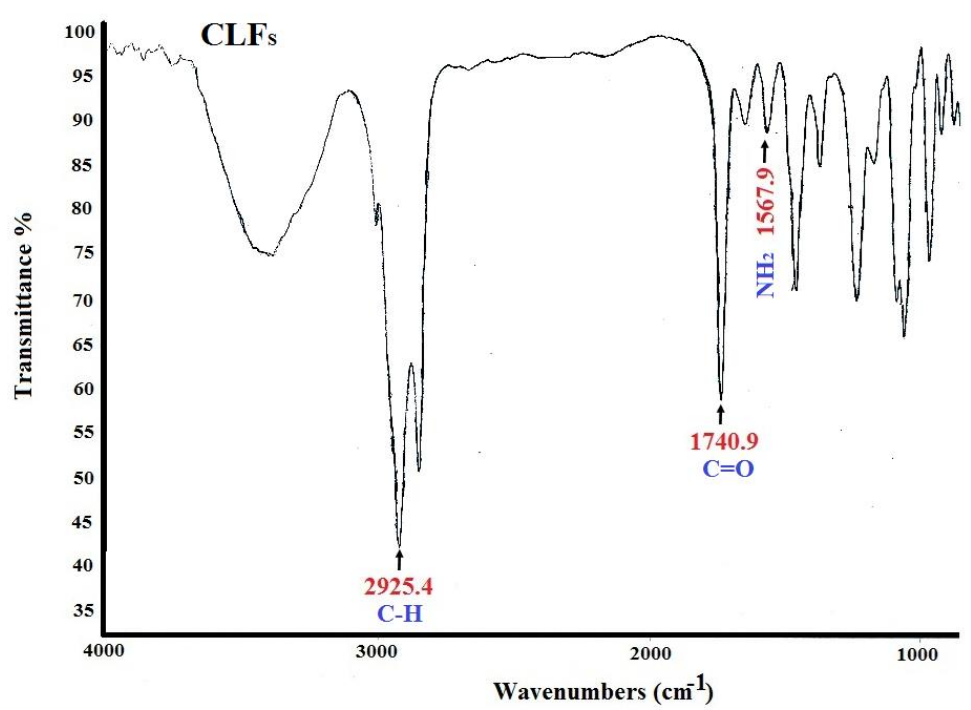

(a)

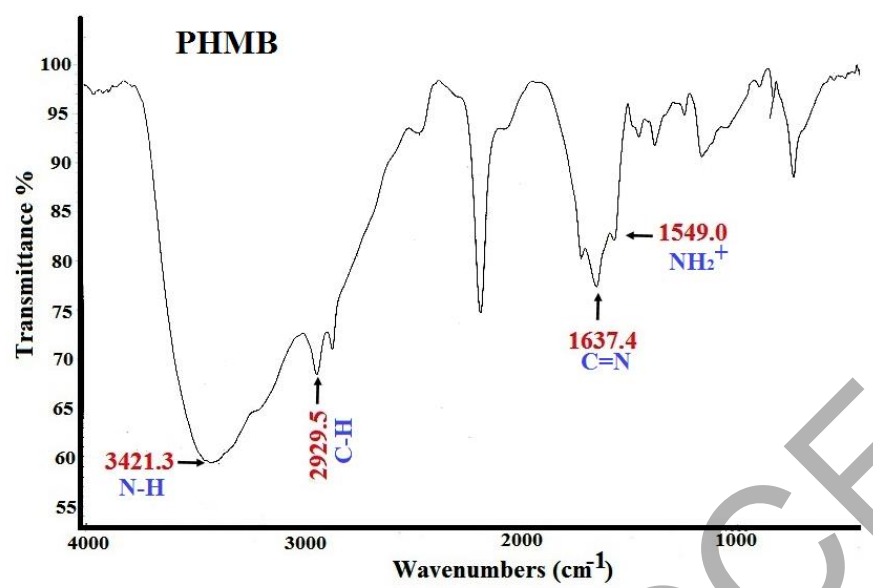

(b)

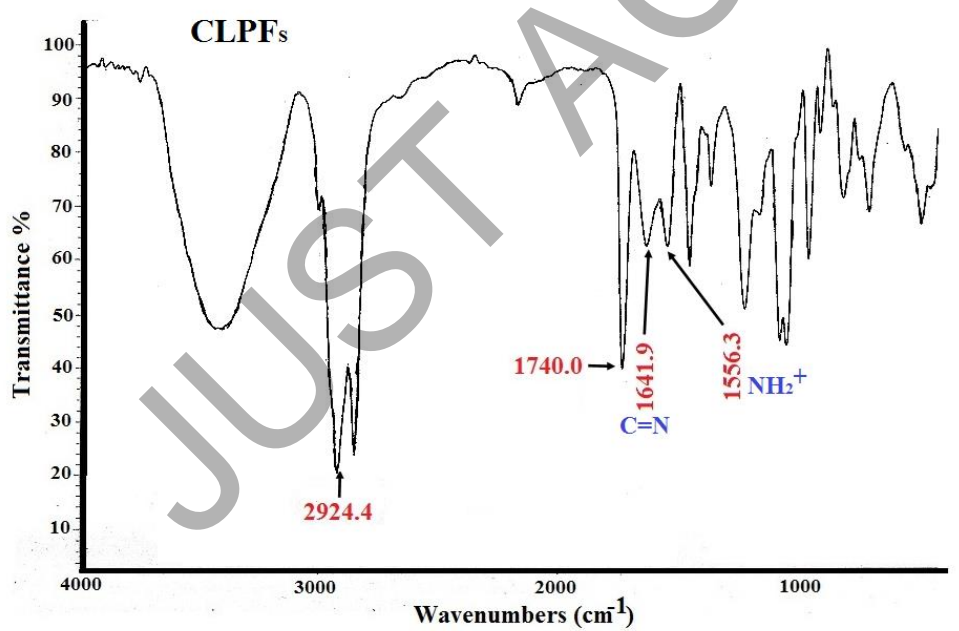

(c)

Figure 1 

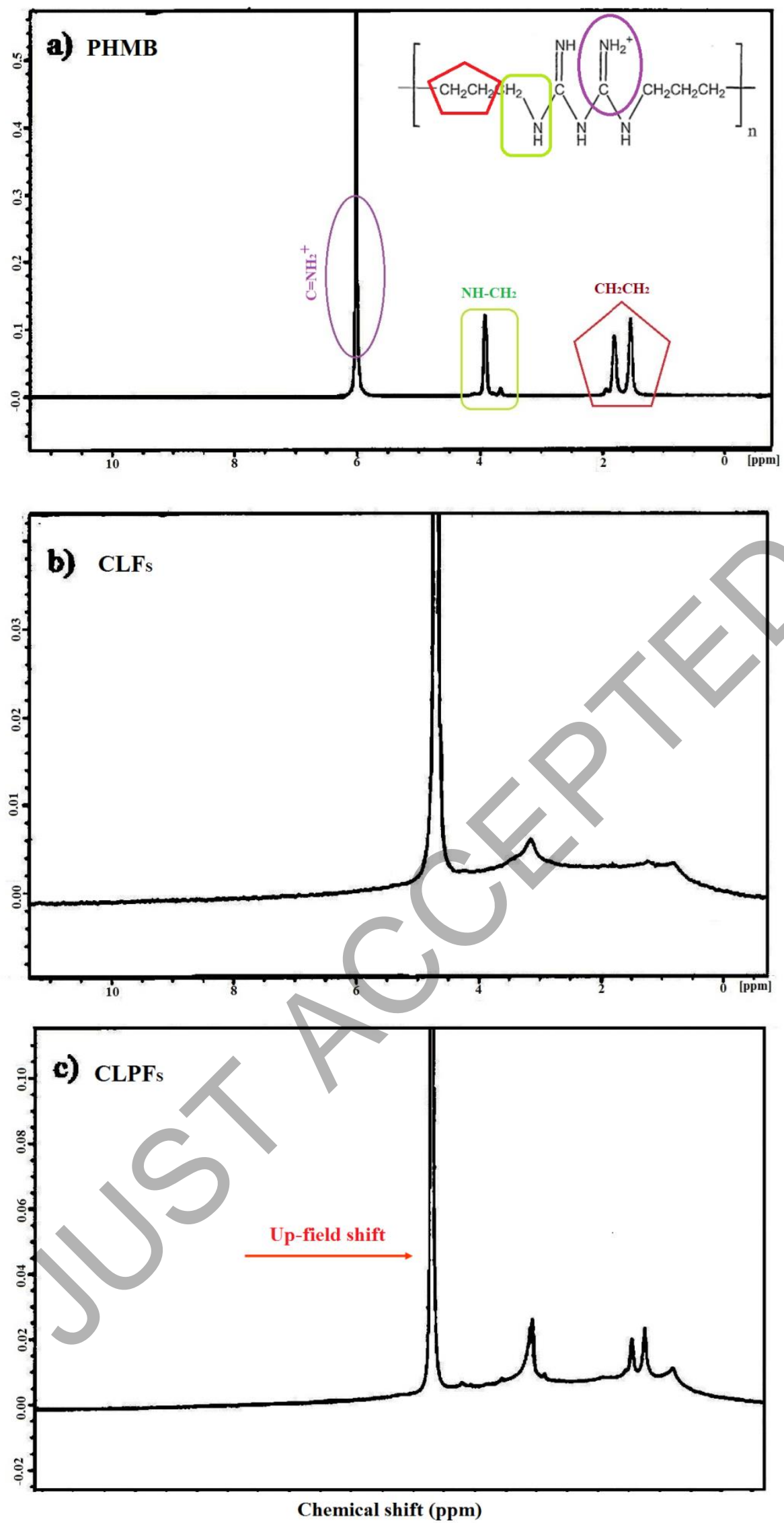

Figure 2 


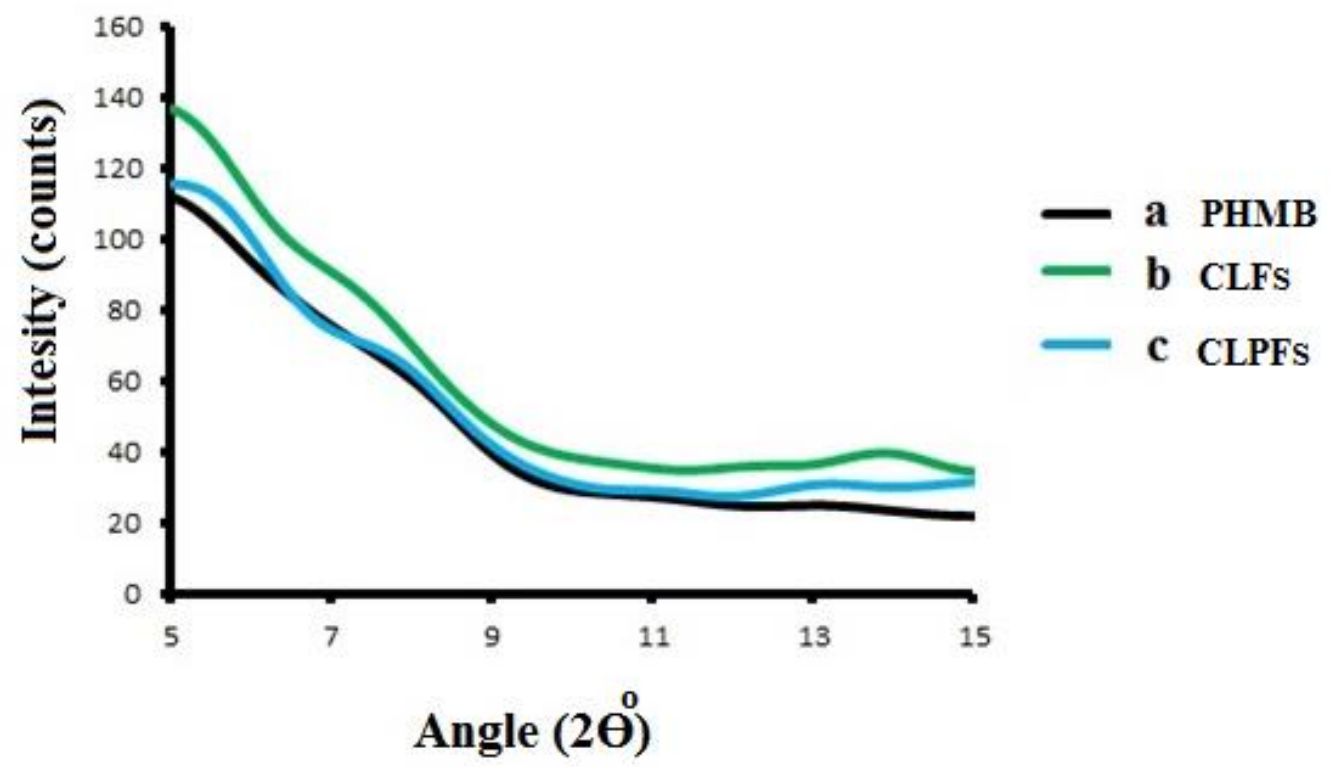

Second order derivative

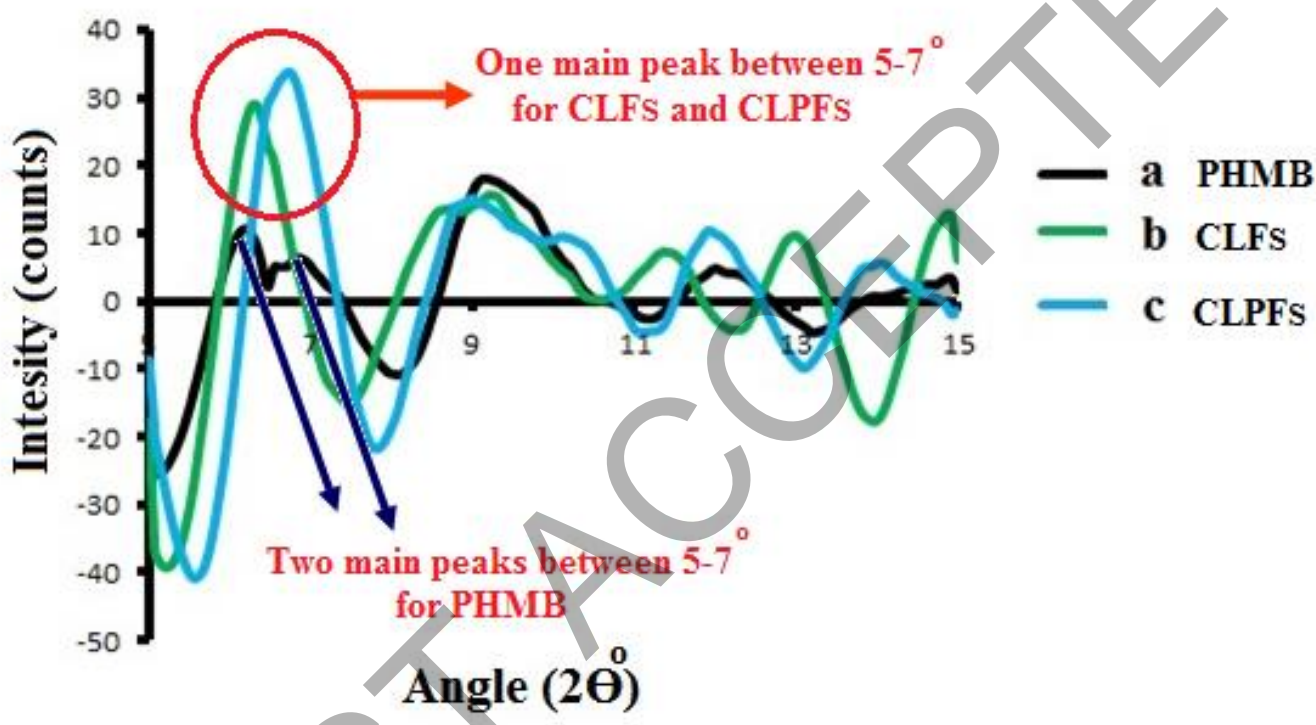

Figure 3 


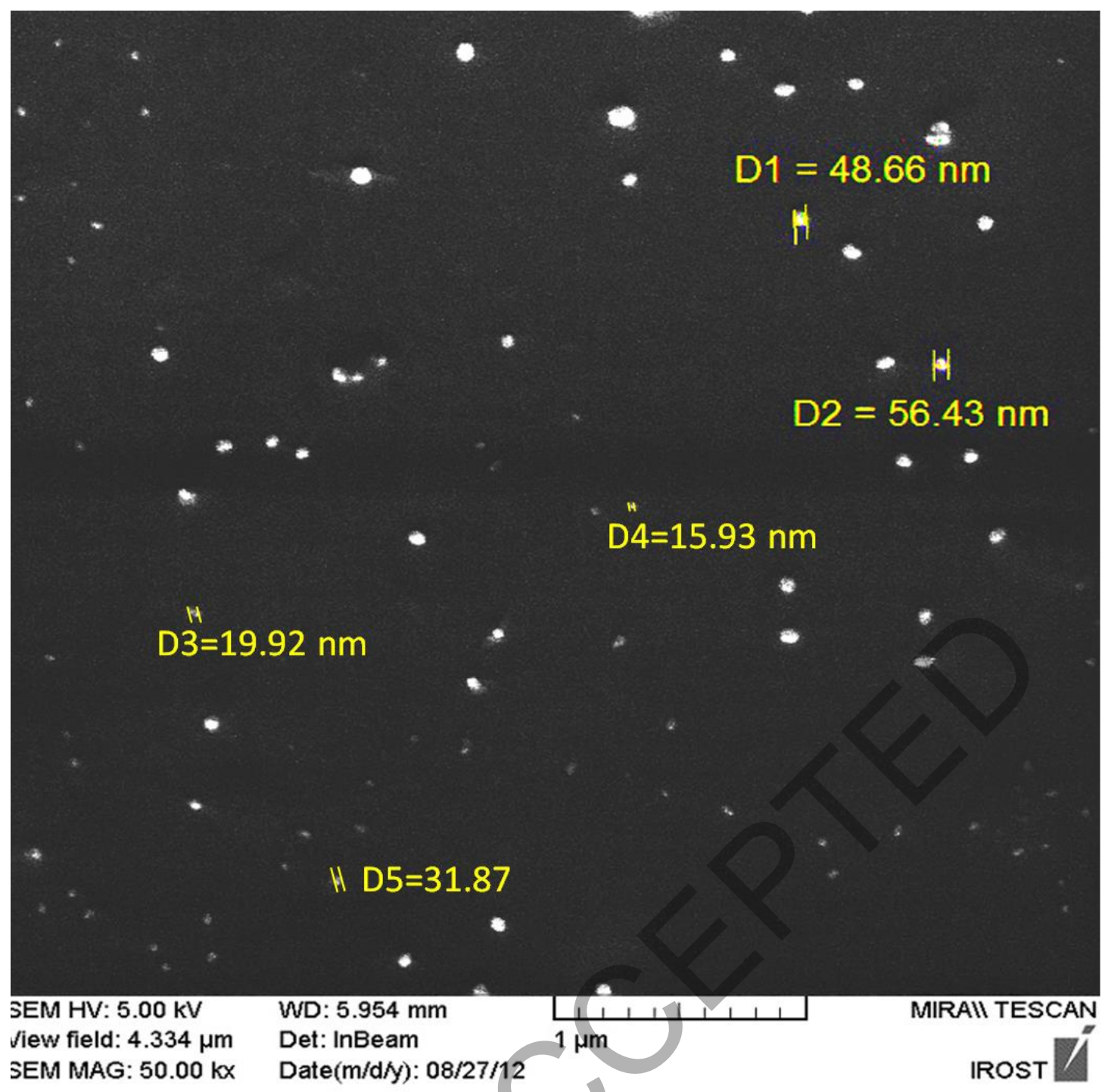

Figure 4 

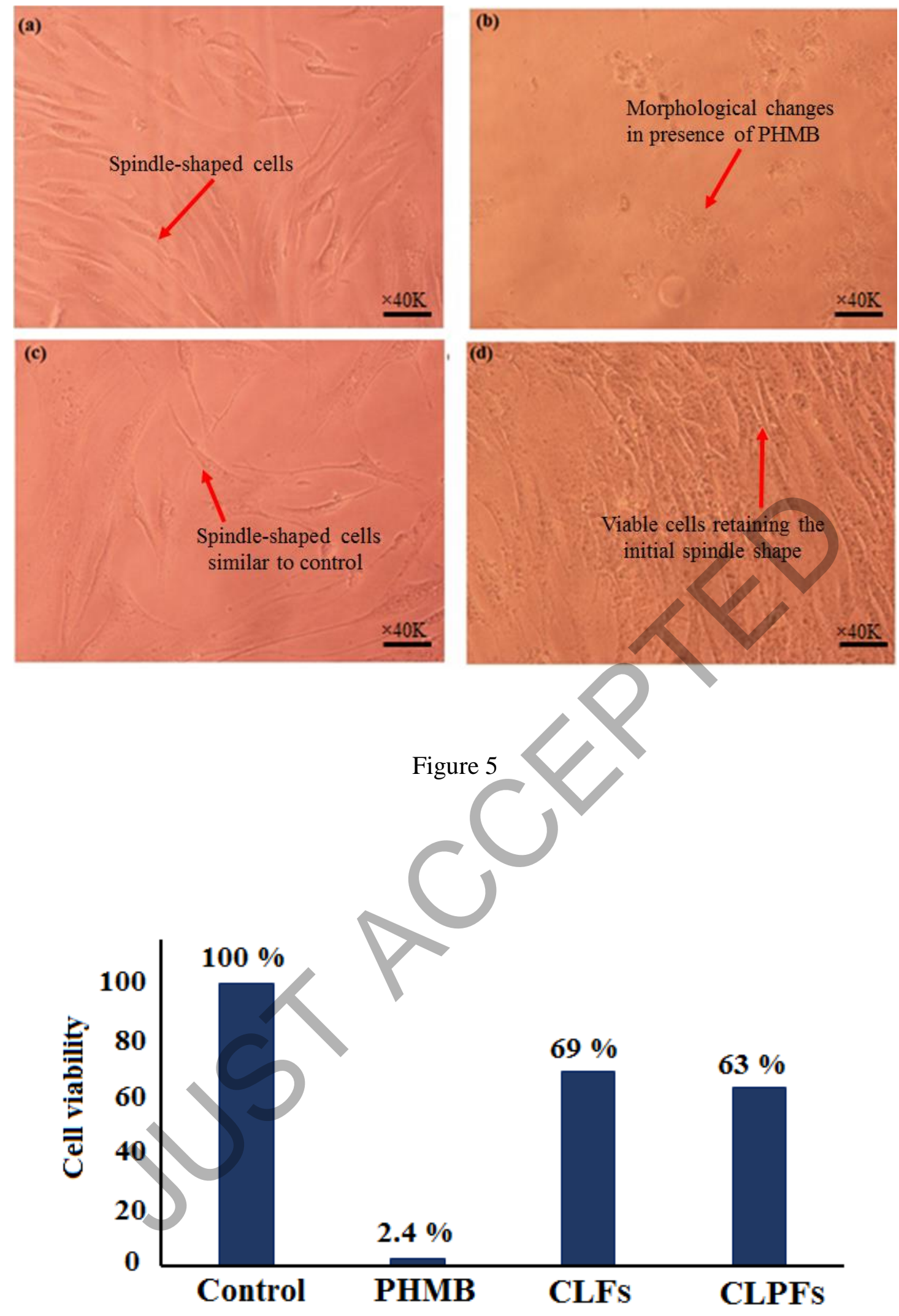

Figure 6 